\title{
Soil stabilisation with alkali-activated agro-waste
}

\begin{abstract}
This study addresses the use of alkali-activated binder to evaluate the feasibility of using this promising technique to stabilise soils. One of the well-known agro-wastes, palm oil fuel ash (POFA), was used as a source binder. Also, sodium hydroxide $(\mathrm{NaOH})$ and potassium hydroxide $(\mathrm{KOH})$ were used as alkaline activators. The influence of four factors including the kind of alkaline activator, the use of source binder, the curing condition and the water content of the soil on the strengthening performance of soil was evaluated according to the improvement of the unconfined compression strength (UCS). At the same alkaline concentration, both sodium hydroxide and potassium hydroxide were able to enhance the strength development rate of specimens. However, potassium hydroxide-POFA-stabilised soil yielded the highest UCS value following a long curing time ( 90 and $180 \mathrm{~d}$ of curing). The size and charge density of the alkaline activator play significant roles in controlling the rate and extent of the activation process for the strength performance. With regard to soil strength improvement, when the POFA content in the activation process increased from $0 \%$ to $15 \%$, the UCS value increased substantially, irrespective of the alkaline activator type. This achievement implies a tremendous effect of this agro-waste on the strength behaviour of treated soil.
\end{abstract}

Keyword: Geoenvironment; Ground improvement; Sustainable development 